\title{
Effect of Different Media on Mycelial Growth of Lentinula edodes
}

\author{
Amoghavarsha Chittaragi*, Ashwani Kumar and Surjeet Singh \\ Department of Plant Pathology, College Of Agriculture, Chaudhary Charan Singh Haryana \\ Agricultural University, Hisar - 125004, Haryana, India \\ *Corresponding author
}

\begin{tabular}{|c|c|}
\hline & A B S T R A C T \\
\hline $\begin{array}{l}\text { K e y w o r d s } \\
\text { Shiitake mushroom, } \\
\text { Lentinula edodes, } \\
\text { Sorghum maal agar, Pearl } \\
\text { millet meal agar, Wheat } \\
\text { meal agar, Potato } \\
\text { dextrose agar }\end{array}$ & \multirow{3}{*}{$\begin{array}{l}\text { Mushroom cultivation is an old age practice and recent advancements in the } \\
\text { production technology has made them to cultivate under commercial scale. } \\
\text { Among various mushrooms cultivated the shiitake mushroom (Lentinula } \\
\text { edodes) is very well known for its medicinal values and hence its } \\
\text { requirement in large scale production is in need. Current evaluation was } \\
\text { done to study the mycelial growth of shiitake on different media derived } \\
\text { from agro-residues. The study revealed that highest growth rate after } 6 \text { days } \\
\text { of incubation was seen in the sorghum meal agar (SMA) with strain OE- } \\
388 \mathrm{~S} \text { ( } 69.9 \mathrm{~mm}) \text { whereas lowest growth rate was observed with strain LE- } \\
16-02 \text { on PDA }(39.5 \mathrm{~mm}) \text {. }\end{array}$} \\
\hline Article Info & \\
\hline $\begin{array}{l}\text { Accepted: } \\
16 \text { March } 2018 \\
\text { Available Online: } \\
10 \text { April } 2018\end{array}$ & \\
\hline
\end{tabular}

\section{Introduction}

Mushroom cultivation is an eco-friendly method of solid waste management. It is evident that mushroom cultivation helps in the biological degradation of natural resources and are eco-friendly, protein rich food and the recent developments in the scientific understanding of mushroom cultivation has aided in improvement of its cultivation technology (Puri, 2011).

Shiitake mushroom species are the edible mushroom which have originated from East Asia and cultivated and consumed in numerous Asian nations. Shiitake mushroom is cultivated throughout the world and contributes around 25 percent of aggregate yearly generation of mushrooms. Shiitakes give good amounts of protein (18\%), potassium, niacin and $\mathrm{B}$ vitamins, calcium, magnesium and phosphorus. They have normal antiviral and resistance boosting properties

Lentinula edodes is a white rot fungus that secretes a class of ligno-cellulolytic enzymes, which permit it to grow on ligno-cellulosic substrates rich in lignin (Leatham, 1986). Shiitake mushroom is routinely cultivated on wooden logs. Inaccessibility of tree $\operatorname{logs}$ requires a look for optional substrates for shiitake and general mushroom cultivation. The availability of the agro-residues after crop 
harvest like straws of various crops as that of wheat, sorghum, bajra, rice has been used as a basal substrate for the cultivation of shiitake in recent times. The use of locally available agroresidues provide a way to minimise the cost of cultivation and also helps to reduce the environmental pollution that occurs due to burning of various agro-residues in the field after the harvest. The growth of Shiitake was found faster on agro-residues compared to the natural $\log$ cultivation (Puri, 2011). Much systemic work has been not done in India with regard to this mushroom and hence there is need to carry out a research using the lignocellulosic agro-residual waste generated in agricultural fields every year. With this background the present study is undertaken to evaluate the effect of different media on growth of shiitake mushroom.

\section{Materials and Methods}

The present investigation was carried out at the Mushroom Technology Laboratory under department of Plant Pathology, CCSHAU, Hisar during 2016-17. The pure culture of $L$. edodes was used for the present investigation were obtained from Directorate of Mushroom Research (DMR), Solan and from Punjab Agricultural University (PAU), Ludhiana and were subsequently evaluated for the growth and development parameters.

\section{Preparation of Potato Dextrose Agar (PDA) media}

Potato dextrose agar (PDA) medium was prepared by using $200 \mathrm{~g}$ peeled potato, $20 \mathrm{~g}$ dextrose and $20 \mathrm{~g}$ agar in a litre of water. The medium was left to cool in the room before 10 $\mathrm{ml}$ of the PDA preparation was dispensed into test tubes, corked and then sterilized at $121{ }^{\circ} \mathrm{C}$ and $1.5 \mathrm{~kg} / \mathrm{cm}^{2}$ pressure.

The test tube containing the $10 \mathrm{ml}$ sterilised PDA was kept in a slanted position. These slants were further maintained to inoculate fungus. To obtain the pure culture, potato dextrose agar (PDA) culture was used. A small bit/disc of tissue was collected from the pure culture of shiitake mushroom and transferred on the sterilized PDA medium under aseptic conditions. This was incubated at $25 \pm 2^{\circ} \mathrm{C}$ for $7-10$ days for sufficient mycelial growth. Pure cultures were obtained by sub culturing.

\section{Preparation of different media}

Four semi synthetic media were used to record their influence on radial mycelial growth of $L$. edodes. The media used for study were potato dextrose agar (PDA), wheat meal agar, Pearl millet meal agar, sorghum meal agar.

The following media were prepared by grinding the $200 \mathrm{~g}$ grains of respective media and then adding the grain powder to $500 \mathrm{ml}$ water for 20-25 min.

The contents are stained through muslin cloth and then volume made to 1 litre and mixed with $12 \mathrm{~g}$ agar and $60 \mathrm{~g}$ dextrose and boiled for few minutes.

\section{Different grain meal agar used}

Sorghum meal agar

Pearl millet meal agar

Wheat meal agar

Potato dextrose agar

The various grain meal agar media prepared were evaluated for radial growth of $L$. edodes strains by transferring a $10 \mathrm{~mm}$ bit of mycelium from pure culture maintained and incubated at $25 \pm 2^{\circ} \mathrm{C}$.

The observations were recorded after one week to analyse the effect of media on radial growth using CRD design with 3 replications under standard laboratory conditions. 


\section{Strains used}

The following strains were used during the research on different media prepared.

\section{LE-16-01 \\ LE-16-02 \\ LE-16-04 \\ OE $388 \mathrm{~S}$ \\ DMRO 27}

\section{Results and Discussion}

The results are depicted in the table 1 which showed that the highest growth rate after 6 days of incubation was seen in the sorghum meal agar (SMA) with strain OE-388S $(69.9 \mathrm{~mm})$ whereas lowest growth rate was observed with strain LE-16-02 on PDA (39.5mm).

The effect of media on the radial growth of the fungus was influenced greatly by the kind of media used. Sorghum meal agar was most favoured by the different strains followed by wheat meal agar, potato dextrose agar and Pearl millet meal agar in the order of preference. The strain OE-388 S showed the fastest growth rate in comparison to other strains which was followed on an average by the LE-16-04, DMRO-27, LE-16-01 and LE16-02 strains respectively.
The growth of strains on SMA (sorghum meal agar) and WMA (wheat meal agar) showed significant difference but the strains LE-16-01 and DMRO-27 were at par with each other. The strains on BMA showed the significant difference except for the LE-16-01, LE-16-04 and DMRO-27 which were at par with each other. Significant difference of growth on PDA was observed with different strains but the strains LE-16-01 and LE-16-04 showed at par growth. Similar pattern has been observed with strains DMRO-27 and OE-388S on PDA.

The strain LE-16-01 exhibited the significant difference in growth on all the four media used but the strains LE-16-02 and LE-16-04 were at par with each other on SMA and WMA. DMRO-27 showed at par growth on WMA and PDA. Other than these, all remaining values varied significantly with each other (Table 1).

The highest growth on sorghum meal agar was exhibited by OE-388S $(69.5 \mathrm{~mm})$ and lowest growth rate was exhibited by strain LE-16-02 $(46.25 \mathrm{~mm})$ whereas the similar trend has been observed with wheat, PDA and Pearl millet meal agar also where highest growth rate was shown by OE-388S $(66.5 \mathrm{~mm}, 59 \mathrm{~mm}$ and $56.5 \mathrm{~mm}$ respectively) and lowest by LE-16-02 (with $39.5 \mathrm{~mm}, \quad 46.5 \mathrm{~mm}$ and $49.25 \mathrm{~mm}$ respectively on PDA, WMA and BMA).

Table.1 Growth rate of $L$. edodes strains on different media

\begin{tabular}{|c|c|c|c|c|c|c|}
\hline $\begin{array}{c}\text { Strain } \\
\text { Substrate }\end{array}$ & LE-16-01 & LE-16-02 & LE-16-04 & DMRO 27 & OE-388S & Mean \\
\hline SMA* & 60.5 & 46.2 & 63.2 & 61.8 & 69.5 & 60.2 \\
\hline PMA & 51.5 & 49.2 & 52.0 & 52.3 & 56.5 & 52.3 \\
\hline WMA & 59.0 & 46.5 & 63.8 & 58.2 & 66.5 & 58.8 \\
\hline PDA & 53.3 & 39.5 & 54.3 & 58.8 & 59.0 & 52.9 \\
\hline Mean & 56.0 & 45.3 & 58.3 & 57.8 & 62.9 & \\
\hline $\mathrm{CD}(\mathrm{p}=0.05)$ & Strains $=1.8$ & Subs & trates $=1.6$ & Intere: & ction $=3.6$ & \\
\hline $\operatorname{SE}(\mathbf{m}) \pm$ & Strains $=0.6$ & Subs & trates $=0.5$ & Interea & tion $=1.3$ & \\
\hline
\end{tabular}




\section{Growth of $L$. edodes strains on different media}

\begin{tabular}{ccccc} 
SMA* & PMA & WMA & PDA \\
\hline LE-16-01 & LE-16-02 & LE-16-04 & DMRO 27 & OE-388S \\
\hline
\end{tabular}

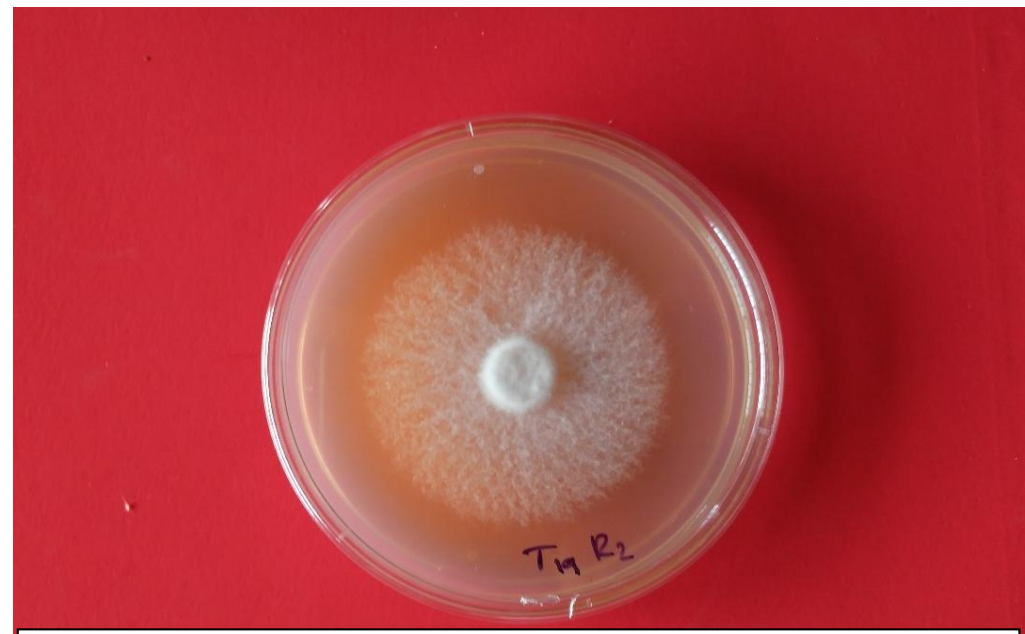

Fig. 1 Growth of Shiitake mycelia on sorghum meal agar media

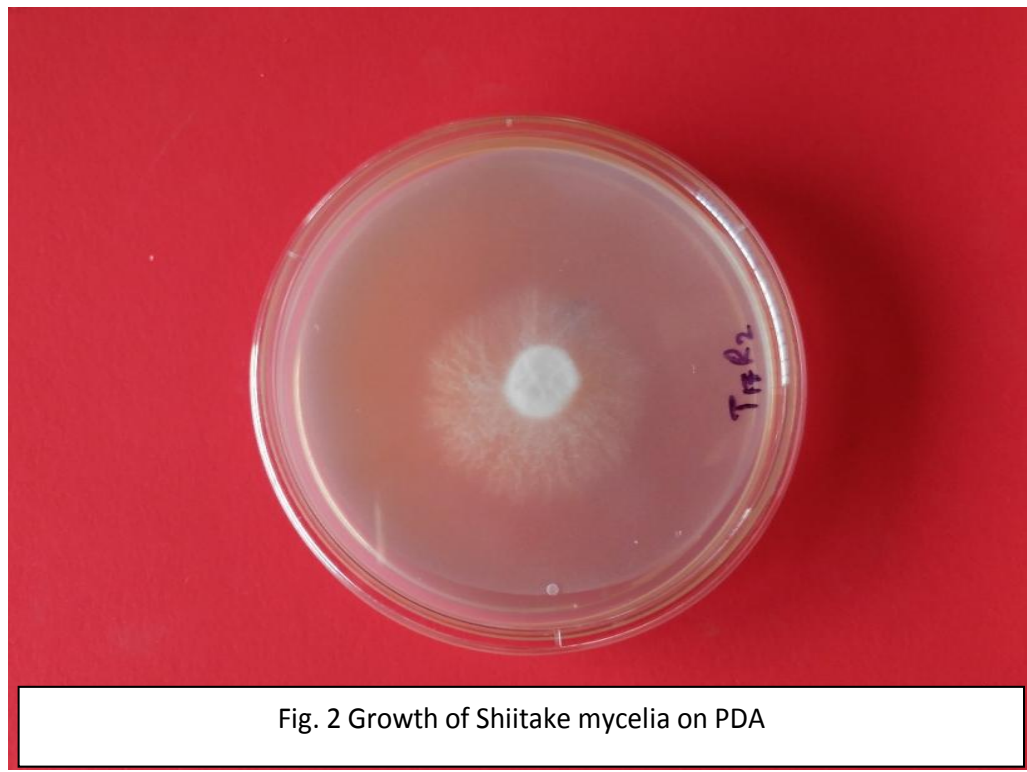


The radial growth was found almost similar for different strains on both sorghum meal agar and wheat meal agar and showed no significant difference but there was a significant difference in radial growth of Pearl millet meal agar and potato dextrose agar with other substrates but strains showed at par growth on both of those media.

Sorghum meal agar was most favoured by the different strains followed by wheat meal agar (WMA), potato dextrose agar (PDA) and bajra meal agar (BMA) in the order of preference. This is in accordance with the results obtained by Furlan et al., (1997) where they evaluated the growth of mycelia $(\mathrm{mm} / \mathrm{day})$ of $L$. edodes at $\mathrm{pH} 6.4$ in the absence of light and at $30^{\circ} \mathrm{C}$ using the malt soya peptone agar (MPA), wheat dextrose agar (WDA) and potato dextrose agar (PDA) with the highest growth being observed in WDA and MPA.

PDA found next best to the sorghum meal agar for the strain DMRO-27 which exhibited the growth of 58.7 and 61.7 on PDA and SMA (sorghum meal agar) which are at par with each other without showing significant difference. Similar results were obtained by Bilay et al., (2000)) after evaluating the mycelial growth by using four commercially available media (malt extract agar, yeast malt extract agar, wart agar and experimental agar medium) and found potato dextrose agar medium as the most suitable medium for the growth of edible fungi. Even Kapoor et al., (1997) found potato dextrose agar (PDA) and malt extract agar media as good source for growth of $P$. fossulatus.

Best mycelia growths were observed on the PDA and Yellow Corn Agar (YCA) with $92.7 \mathrm{~mm}$ and $92.0 \mathrm{~mm}$ respectively (Gbolagade et al., 2005). Even in the current study the PDA exhibited the good performance but after SMA and WMA.
Glucose and ammonium chloride acts as the good carbon and nitrogen source for optimal mycelial growth (Song et al., 1987). Kaur and Lakhanpal (1995) found maximum mycelial growth on media where dextrose was used as carbon source. Similarly, good biomass of mycelium (Lentinula edodes) found on a medium containing glucose as the carbon source (Sakamoto et al., 1978). Hence, it could be assumed that media containing dextrose or glucose supported maximum mycelial growth.

\section{References}

Bilay, V.T., Solomko, E.F. and Buchalo, A.S. 2000. Growth of edible and medicinal mushroom on commercial agar media. Science and cultivation of edible fungi. Proceeding of the 15th International Congress on the Science and Cultivation of Edible Fungi, Masstricht, Netherlands, 15-19 May, pp.779-782.

Furlan, S.A., Virmond, L.J., Mires, D.A., Bonatti, M., Gem, R.M.M. and Jones, R. 1997. Mushroom strains able to grow at high temperatures and low $\mathrm{pH}$ values. World Journal of Microbial Biotechnology. 13: 689-692.

Gbolagade, J.S., Fasidi, I.O., Ajayi, E.J. and Sobowale, A.A. 2005. Effect of physicchemical factors and semi-synthetic media on vegetative growth of Lentinus subundus (Berk.), an edible mushroom from Nigeria. Food Chemistry. 99: 742747.

Kapoor, S., Sharma, A., Phutella, R.P. and Sodhi, H.S. 1997. Physiological studies on Pleurotus fossulatus. Paper presented in Indian Mushroom conference organized by MSI and NRCM, Solan from 10-13th September, pp. 65.

Kaur, M.J. and Lakhanpal, T.N. 1995. Effect of Nutrient elements, vitamins and growth regulators on the vegetative 
growth of Lentinusedodes. Journal of Mushroom Research. 4(11): 11-14.

Leatham, G.F. 1986. The ligninolytic activities of Lentinus edodes and Phanerochaete chrysosporium. Applied Microbiology and Biotechnology. 24: 51-58.

Puri, S. (2011). Agricultural wastes as substrate for spawn production and their effect on shiitake mushroom cultivation. International Journal of Science and Nature. 2(4): 733-736.
Sakamota, R., Niimi, T. and Takahashi, S. (1978). Effect of Carbon and nitrogen sources on submerged culture of edible fungi. (Studies on submerged culture of edible fungi Part-I). Journal of the Agricultural Chemical Society of Japan. 52(2): 75-81.

Song, C.H., Cho, K.Y. and Nair, N.G. 1987. A synthetic medium for the production of submerged cultures of Lentinus edodes. Journal of Mycologia. 79 (6): 866-876.

\section{How to cite this article:}

Amoghavarsha Chittaragi, Ashwani Kumar and Surjeet Singh. 2018. Effect of Different Media on Mycelial Growth of Lentinula edodes. Int.J.Curr.Microbiol.App.Sci. 7(04): 2193-2198. doi: https://doi.org/10.20546/ijcmas.2018.704.249 